\title{
Part time training in general medical specialties: is it any use?
}

\author{
C W BURKE
}

It has recently been said that part time medical work "will have to be accepted by employers and colleagues as a norm." feared wastage of graduates who cannot work full time because of non-professional commitments is a matter not so much of unemployment (which is as low as $9 \%$ among women doctors) ${ }^{2}$ as of doctors finding themselves unable to train or practise their specialty of first choice. ${ }^{3-6}$ Hence there is now a national scheme ${ }^{7}$ for part time training in hospital posts at all postregistration levels. It is designed for those who cannot train full time because of "domestic commitments, disability, or ill-health."? The quality of and arrangements for part time training in general medical subspecialties were surveyed in the recent report to the Royal College of Physicians. ${ }^{8}$

The actual usefulness of part time training in enabling doctors to achieve satisfactory careers in their first choice specialty has been much less discussed. The proportion of doctors who require part time general practice training is as low as 5\%.4 Only a small number of the first brave pioneers of part time training in Oxford are now practising in acute hospital specialties, ${ }^{9}$ and the future of part timers training in anaesthesia has been reported with only moderate optimism. ${ }^{10}$ Information on the availability of part time training ${ }^{11}$ outstrips assessment of its usefulness in practice. Little has been written about part time career posts. ${ }^{2}$ Furthermore, part time medicine is disconnected from manpower planning, the Short report, for instance, confining itself to suggesting that part time associate specialist posts should be available. ${ }^{12}$

This paper supplements the report to the Royal College of

\section{Radcliffe Infirmary, Oxford OX2 6HE}

C W BURKE, DM, FRCP, consultant physician, former RCP regional adviser
Physicians with a personal view and gives some examples from the replies to the survey questionnaires from those in part time training.

\section{Does part time training open up acute specialties?}

Part time training is usually satisfactory in "sessional" specialties but is much less so in acute specialties (especially at senior house officer and registrar level). ${ }^{8}$ Obviously, doctors with a non-medical commitment will find sessional specialties easier; the question is whether changing the system can improve choices open to these doctors.

The variety of responses from the replying part timers suggests that there is no uniform solution. Some gave reasons for the problem with acute work such as:

"A lack of respect from junior or nursing staff, who were less likely to take notice of your decisions."

"Limitations of not being easily available for emergency and generally urgent work; problems with day to day care of inpatients arise if not in hospital for more than one day at a time."

"I am not as experienced practically in intensive neonatal care as some of my colleagues."

"The day to day experience of full time posts is irreplaceable."

"Part time training cannot ever match full time however long it takes, as of necessity continuity of patient care is limited."

"Lack of continuity is a big problem-you are very dependent on others' observations of the patients."

"One is not available out of hours to see through clinical problems or deal with emergencies."

In contrast, other replies stated that there was no problem with acute work, such as:

"Important to put in extra hours whenever it is in the interest of the patient, colleagues, or unit staffing."

"Part timers must be prepared to become part of a unit and pull their weight."

"Personally, I found the majority of colleagues very welcoming and 
helpful ... many doctors expect part timers to be doing clinics only ... Such attitudes are not helped by those who don't do their sharefor example, refuse to do any weekends."

"Yes, it is qualitatively the same (as full time): on call commitment is identical with full time posts."

"My particular post gives me excellent exposure to clinical problems in a busy district general hospital as well as at a teaching hospital."

"Yes (it is as good as full time). But requires dedication some will find difficult. To achieve this and be a successful wife and mother is very demanding."

This variability in response shows a range going from those who need no help as they find it easy to accommodate nonmedical commitments even within a full time career to those who will be little helped even by profound changes in medical practice or training because their priorities lie so far from their career. Some doctors in the middle can-and should-be helped by the provision of more part time training posts in acute specialties, but this will not solve the problem for many. I conclude that short of a revolution in social habits it will be impossible to prevent this unofficial specialty diversion by chromosomal sex, and it should be recognised in two ways. Firstly, the manpower authorities should include it in their calculations. Secondly, the expectations of students should be tempered by advice that acute specialties may not, in practice, suit them as individuals. The earlier this is perceived the less the disappointment.

Much depends on the reason for the choice of specialty in training posts. With proper planning of one's life it is not too difficult to acquire the brief element of acute experience at senior house officer level that is needed for vocational training for general practice, the other elements being relatively easily located in part time training. At the other extreme, destruction of one's marriage to get acute experience with the long term objective of being an unplaced part time cardiologist would be unwise. Alternatively, acquiring acute experience before going part time enables the determined graduate with an accommodating domestic partner to continue training even in "tough" specialties despite non-medical commitment. It is clear that only partial solutions are possible however profound changes in the system might be. I would counsel gradual change-more part time training posts with acute experience, upgraded by the recommendations in the report to the Royal College of Physicians $^{8}$ but by evolution rather than revolution.

\section{Higher degrees}

For the determined few, or those whose non-medical commitments allow, part time posts can enable them to get the membership of the Royal College of Physicians. But this is not so for the majority, as the following replies show:

"My main regret is not having been advised to take a higher degree such as MRCP soon after qualifying, as it is virtually impossible years on when all the textbooks have changed ... and one now needs to work in general medicine for one year for the exam, which I couldn't fit into family commitments at this stage."

"I was supposed to be doing my part $2 \mathrm{MRCP}$... . it would require me to work virtually full time to get the necessary experience."

"I would have found it very difficult to attempt higher exams during part time training because of family commitments."

This is a further argument for completing general professional training before going part time.

\section{Part timers and the consultant grade}

Given that the present scheme enables some senior registrars to emerge from part time training at a reasonable age with copper bottomed credentials, does it get them any further ?

Doctors with domestic commitments cannot necessarily by magic suddenly become full time when they complete senior registrar training. ${ }^{3} 91^{0}$ Therefore, the argument goes, more part $\frac{\text { W }}{7}$ time consultant (and general practitioner) posts must be provided, and of course for best use of medical personpower ${ }_{c}$ there must be the built in option of going full time when the non-medical commitments later disappear. I leave aside the $\frac{\rho}{\bar{F}}$ question of how to plan a thoracic service, say, with a young full timer and two part timers who may become full time at any point $\mathbb{\Phi}_{\infty}$ they might choose from next year to five years' time.

Are part time consultant posts clinically viable? Clearly, in sessional specialties they already are. In acute specialties the $\Rightarrow$ credo in recent years has been "geographically full time." I have $\stackrel{5}{?}$ become unconvinced since the survey that this is as important as? fashion suggests. Many of my colleagues in district hospitals $\frac{\overline{\bar{O}}}{\overline{\mathrm{N}}}$ serve two or more hospitals; I serve two teaching hospitals; some $\frac{\text { ? }}{\sigma}$ of our most eminent colleagues spend as much time in London $\mathbb{\varnothing}$ or Montreal as they do at their base hospital; in Australia and the United States the visiting physician is the norm and mainstay of the unit, although there is usually a full time director, which is ${ }_{-}$ important. Surely there is no difference in value between the $\vec{\omega}$ part timer who leaves his ward round for Harley Street and the $\stackrel{\odot}{\circ}$ one who leaves to collect her children from school ? Provision of $\frac{}{3}$ more part time consultant posts would help the attainment of highly useful and satisfying careers by some of the graduates in $\mathscr{\complement}^{\circ}$ the survey. But it will be of limited use because of geographicalos immobility.

\section{Geographical immobility}

Geographical immobility is the biggest single factor in the ${ }_{0}^{\infty}$ part time debate and deserves much more analysis in my opinion. It operates right throughout the career of the part timer.

Here are the comments of three trained senior registrars:

“. . . The difficulty now is that there is only one consultant post $\mathrm{I}_{\mathscr{0}}$ can apply for. If a full timer applies for it I cannot, being part time, $\omega$ offer much competition."

"There is no point in creating part time training posts unless once they are trained there are plans to appoint them as consultant in the area in which they live-or get divorced."

"... There is no guarantee at the end of the day of a job in ... where I am geographically tied by my husband's job."

Short of jobs for the girls (see below) there is no solution to $\overrightarrow{\overrightarrow{0}}$ this intensely personal problem of geographical immobility limiting career posts.

Even for those entering part time training grades the question is whether it can be "fixed up for you locally." They need to locate a hospital that can provide the required experience, with a consultant trainer who understands the special needs and may have to perturb his practice to serve them-and all this withindriving distance. The senior registrars returning our question- 0 naires were often working in district general hospitals, unlike their full time counterparts who are mostly in teaching hospitals. 음 By being present in district general hospitals they may beN helping their institutions, but at a personal price as the following examples show:

“. . . Despite the adequacy of the clinical material here (in a small 0 district general hospital) the learning experience can never quite come $N$ up to that of a large academic unit as the consultants are not geared to teaching and there is inevitably less throughput of ideas, fewer visiting lecturers, etc."

". . . I have to live where I do because of my husband's post and therefore have no choice."

". . . It was intended that I should specialise in dermatology. However, to do this I would have had to spend two full days a week in $\frac{\text { ? }}{\mathbb{P}}$ ... which would have involved three hours' travelling each day. This $\stackrel{\mathbb{Q}}{\mathcal{Q}}$ was impracticable and in any event there is no guarantee of a job at $\stackrel{\mathbb{Q}}{\mathscr{Q}}$ the end of the day in .... where I am geographically tied by my husband's job.... My [part time senior registrar's] job was terminated, and I am now unemployed and looking for clinical assistant sessions."

"... To be competitive you need similar specialist training to fullo time and this usually means at a specialist centre. This is not possible for most women with family commitments and defeats the whole 
purpose of the training scheme, which is locally based due to those commitments."

Even with the more junior grades there were many examples of people driven into inappropriate or even unwished for posts because there was no room for them to acquire the experience that they needed locally. Several referred to this as "marking time," but they were officially in "training" posts.

\section{Jobs for the girls}

The national scheme training grades $^{7}$ are all personalised posts, neither established nor competitive, and are extra. Thus the principle of "jobs for the girls" is already accepted. Although I accept that the numbers can be usefully increased, the pace will have to be slow as these posts can cause damage in three ways, all of which appeared in the survey replies. Firstly, they sometimes raised the trainee's expectations beyond a realistic level, deceiving her that she was training for something that she was not. Secondly, the posts may be so visibly artificial as to label a trainee substandard afterwards. Thirdly, some posts interfered with the training of others by diluting the experience available. The report to the Royal College of Physicians makes recommendations to limit this damage. In addition, at senior registrar level the appointment, some say, is tantamount to appointing a consultant, and if the appointee is geographically tied the consequence is obvious. Finally, the manpower regulation of PM(79)3 senior registrar posts is national and not sensitive to local workload, even travelling with the senior registrar as she moves between regions if she is not immobilised. But manpower authorities still seem to have anosmia for nastier issues relating to career posts already wafting under the noses of appointment committees and educational authorities. I have been surprised by the number of people who say that the only way to solve the dilemma of medical womanpower is to create career posts locally to utilise the talents of doctors fixed in the area.

In a National Health Service whose financing is too slender for all its tasks the creation of a career post should happen only in response to clinical service need. Furthermore, the best possible person should be found to fill it. Ian Kennedy ${ }^{13}$ believes that medicine exists to serve the needs of doctors already.

The service need may be changed in ways not connected with the workload-for example, expansion of the consultant grade could make room for lots of part time consultants. But within a given district general hospital there would more often than not be a mismatch between the supply of part timers geographically tied to it and the number required in a particular specialty.

Jobs for the girls suggests reduction of competition for career posts but it also implies random variability in competition and unfairness. There would be tremendous variation in the numbers of geographically tied applicants from place to place, and those who are not so tied will be competing with each other much more strongly as they gather like bees round the more desirable advertisements. Moreover, the harassed full timer has to be fitted in somewhere. The principle of jobs for the girls may or may not be acceptable, but its practice is likely to be difficult.

The great exception is the associate specialist grade. This offers many opportunities to geographically tied part timers, tailored more easily to service needs because the area of service is usually more limited than that of a consultant. In addition, part time training is a good route to associate specialist posts, as it requires only three years' whole time equivalent service in relevant experience in the registrar grade, and there is no general experience requirement. This makes a career as an associate specialist an attractive soft option for many part timers. ${ }^{8}$ It seems not unreasonable that non-medical commitment should reduce medical ambition. Presumably there is a limit to the proportion of the total service that may be provided in this way, however, and if (say) geriatrics became saturated with associate specialists consultant manpower planning would be impossible.

\section{Conclusions}

Between the extreme views that all possible means of employment must be found for geographically or domestically tied doctors, or alternatively that all must take their tumbles in open competition, there is as yet no reconciliation. Experience overseas is unhelpful. In Australia the problem does not exist. In Brazil there are extended families and servants. In the United States the preoccupation is with the economic and professional status of women doctors ${ }^{14} 15$ rather than with the part time issue. In Europe the European Community has decreed that "any derogation (from full time training) should be limited and strictly regulated." 16 We may be first in the field or merely making a mountain of a molehill.

The limitations of part time training in general medical specialties have as much to do with the lives of those undergoing training-for example, geographical immobility, domestic commitment-as with the availability and quality of part time training.

In addition, part time training falls far short of fulfilling the career aspirations of all medical graduates whose domestic commitments interfere with their medical ones. Achievement of career posts continues to be limited by lack of part time posts, geographical immobility, the greater suitability of some specialties than others for part time work, and attitudes among young graduates and the "establishment."

I thank all those part timers who returned questionnaires, the regional advisers of the Royal College of Physicians, and postgraduate authorities and specialists in community medicine for their help. I particularly thank the president and officers of the college for their encouragement, and Dr N A Black for his collaboration.

\section{References}

1 Anonymous. Part-time training and working in the NHS. Hospital Update $1982 ; 8: 389$.

2 Ward AWM. Careers of medical women. Br Med f 1982;294:31-3.

${ }^{3}$ Swerdlow AJ, McNeilly RH, Rue ER. Women doctors in training: problems and progress. $\mathrm{Br}$ Med $\mathcal{F} 1980 ; 281: 754-8$.

4 Varnam M. Part-time training: is it viable? Br Med $\mathcal{F} 1982 ; 285: 1016-7$.

${ }^{5}$ Henryk-Gutt R, Silverstone R. Career problems of women doctors. $\mathrm{Br}$ Med F 1976;ii:574-7.

B Hutt R, Parsons D, Pearson R. The timing of and reasons for doctors' career decisions. Health Trends 1981;13:17-20.

7 Department of Health and Social Security. Opportunities for part-time training in the NHS for doctors and dentists with domestic commitments, disability or ill-health. Personnel memorandum, PM(79)3. London: DHSS, 1979.

${ }^{8}$ Burke CW, Black NA. Part time senior registrars, registrars, and senior house officers in general medicine and its subspecialties. A report to the Royal College of Physicians. Br Med f 1983;287:1040-4.

9 Swerdlow AJ, Rue ER. Part-time medical training: 15 years' experience in the Oxford region. $\mathrm{Br} \mathrm{Med} \mathcal{F} 1981 ; 283: 1371-3$.

${ }^{10}$ Eaton JM. Survey of part-time senior registrar anaesthetists. $\mathrm{Br} \mathrm{Med} \mathcal{F}$ $1980 ; 281: 758-60$.

11 Council for Postgraduate Medical Education in England and Wales. Parttime in medicine. London: CPME, 1981.

12 Anonymous. House of Commons Social Services Committee reports. $\mathrm{Br}$ Med f $1981 ; 283: 997-8$.

13 Kennedy I. Unmasking medicine. We must become the masters of medicine, not its servants. The Listener 1980 Nov 6:600-4.

${ }^{14}$ Rinke CM. The professional identities of women physicians. $\mathcal{F} A M A 1981$; $245: 2419-21$.

${ }^{15}$ Rinke CM. The economic and academic status of women physicians. ҰAMA $1981 ; 245: 2305-6$.

${ }^{16}$ Advisory Committee on Medical Training. Opinion on the part time training of specialists. Brussels: Directorate-General for Internal Market and Industrial Affairs of the Commission of the EEC, 1978.

(Accepted 20 Fuly 1983) 